\title{
Intercultural Learning may be Impossible in Education Abroad: A Lesson from King Lear
}

\section{David Wong}

Michigan State University

\begin{abstract}
:
Intercultural learning requires reflection; education abroad scholars and practitioners hold this belief to be self-evident. Becoming more aware of both others' and one's own culture requires intentional reflection, often facilitated by an expert. However, the practice of guided reflection rests upon the precarious assumption that learners can be honest about deeply personal experiences when they reflect. I make the argument that the truthfulness of students' reflections cannot be assured because guided reflection has become a ritual. Students are well aware of the social norms of guided reflection since it is such a common activity in the orthodoxy of liberal arts learning. As a result, they are more concerned about proper performance than truthful expression. Scenes from Shakespeare's King Lear are used to illustrate the argument that truthfulness of expression cannot be assured in situations in rituals - that is, when a certain kind of performance is expected. If honesty cannot be assured, then guided reflection may be fundamentally unsuited as a means to promote intercultural learning. Four alternative behavioral conventions are presented to help students free themselves from the constraints of academic rituals: don't act like a good student, don't work so hard, don't think so much, and don't talk so much. Finally, three virtues are offered that characterize students who can break free from the constraints of academic rituals: honesty, ignorance, and courage.
\end{abstract}

\section{Reflection gone awry}

I couldn't believe what I was hearing.

Two of my education abroad students had just taught a lesson in school for refugees. The lesson had been...not very good, at all. I had just asked them to tell me how they felt about their recent experience.

"Yes, I thought it went well!" said one of the students. Smiling, she looked to her teaching partner who cheerfully agreed, "It was good! I think the students enjoyed the lesson!" I couldn't believe what I was hearing. Were these two students blind to what just happened only five minutes earlier? Don't they remember the discomfort in the room as they stood there asking....

"Anyone? Who can give me an example? Anyone?" The small group of middle school students sat silently. These students were recent refugees and immigrants from war-torn Syria, Afghanistan, and Eritrea. My education abroad students had been asked by the school to teach lessons to help these students learn English. In response, my students had prepared a music lesson meant to inspire appreciation for the variety and history of rap music. However, the many cultural references and terms meant to interest the students instead left them silent. My education abroad students had 
clearly misjudged these immigrant students' level of prior knowledge and English comprehension. As the lesson progressed, the periods of silence grew longer. In the back of the classroom, the regular classroom teacher and I did our best to maintain pleasant expressions on our faces. The awkwardness was palpable.

...I waited a bit, hoping to hear something more honest, more accurate in my students' reflection on their intercultural teaching experiences. But, I didn't. Soon, we were joined by the other students in our education abroad program, each eager to share their own teaching experiences. I was unsure how to move forward with the reflection, not wanting to diminish our group's sense of relief and excitement. Anyway, it was time to leave. After taking a group picture at the school's entrance, our group walked to the bus stop-laughing and chatting noisily.

\section{Reflection, honesty, and intercultural learning}

Intercultural learning ${ }^{1}$ is an important goal for many education abroad programs. ${ }^{2}$ However, scholars have argued that these programs often fall short in promoting significant growth in this area. There are numerous reasons, but analysis often points to the lack of guided reflection as one of the main reasons why overseas experiences fail to foster students' intercultural competence. (Cohen et al., 2005; Engle, 2013).

However, research evidence supporting the effects of guided reflection has been inconclusive. Large-scale studies comparing different instructional treatments typically do not show significant differences favoring programs that incorporate more intentional, guided reflection (Cohen et al., 2005). In addition, Wong (2015) has pointed out that disappointing gains in intercultural learning might be attributed to unreasonable expectations of the magnitude and rate of change during education abroad programs.

In this article, we step back to examine the broader "self-evident" belief that guided reflection supports intercultural learning. As the real example at the beginning of the piece illustrates, sometimes things go awry when education abroad students reflect on their intercultural experiences. In what follows, an excerpt from Shakespeare's King Lear illustrates how difficult it is to assure truthfulness when we ask someone how they feel. When truthfulness cannot be assured, we can question whether guided reflection may be an unreliable means for promoting intercultural learning in education abroad programs.

\section{A lesson from King Lear}

In the first scene of Shakespeare's King Lear, the aging king asks his three daughters to express their love for him. The eldest, Goneril, begins, "Sir, I love you more than words can wield the matter." She describes her love as greater than eyesight, space, and freedom. The artful flattery

\footnotetext{
${ }^{1}$ Deardorff (2004) has defined "intercultural competence" as "the ability to communicate effectively and appropriately in intercultural situations based on one's intercultural knowledge, skills, and attitudes" (p. 194). At the core of this view of intercultural competence is "cultural awareness, both of one's own as well as others' cultures." (Deardorff, 2006, p 247.) The emphasis on awareness and attitude is also central to intercultural sensitivity, as conceptualized by Bennett (1993) and Hammer et al. (2003). By intercultural learning, I am referring to the process of becoming more interculturally competent or sensitive.

${ }^{2}$ Not all education abroad programs have intercultural learning as a primary goal. Instead, disciplinary or language learning may be main emphasis.
} 
continues with Regan, the middle sister, as she claims to be "an enemy to all other joys," except her love for her father.

Finally, King Lear turns to Cordelia, his youngest and favorite daughter, to hear her expression of love. Here's an abbreviated version of their exchange:
King Lear
Strive to be interess'd; what can you say....
Cordelia
Nothing, my lord.
King Lear
Nothing will come of nothing: speak again.
Cordelia
...I cannot heave my heart into my mouth...

Shakespeare, Act 1. Scene 1. (Shakespeare, 1999)

No doubt Cordelia loves her father deeply; the rest of the play bears this out. Cordelia agrees with Goneril and Regan that words cannot adequately express her love. However, unlike her sisters, Cordelia refuses to even try. Why?

In this situation, a number of things prevent Cordelia from expressing her love: a father is asking his daughter, the setting is very public, a reward is contingent on a proper response, expressions of love are so common as to be trite, and love cannot be easily expressed on demand. In this situation, Cordelia realizes the honestly and sincerity of her expression of love is impossible to assure.

A similar scene is played out in education abroad programs: instructors or leaders ask their students to reflect upon their experiences by sharing their reactions to intercultural experiences. The honesty of students' reflection is critical. Global learning and personal growth of any kind are more likely when individuals see their experiences in an honest light: the less distortion the better. However, honest reflection cannot be assured in the context of guided reflection. Why not? Just as Cordelia's expression of love was constrained by the social forces of the situation, education abroad students' reflections on their experiences are similarly constrained.

\section{If honest guided reflection is impossible, intercultural learning is impossible}

Here's the central argument of this essay:

- Intercultural learning requires honest consideration of one's experiences; guided reflection is the typical and recommended method.

- Guided reflection is a ritual constrained by social norms for proper behavior.

- As a ritual, honest expression of one's personal thoughts is impossible to assure.

- Without honest expression, intercultural learning is compromised. 
Before proceeding, let's define reflection, intercultural learning, honesty, and ritual.

\section{Reflection}

One of the most widely cited perspectives on learning in the education abroad literature is Kolb's (1984) learning cycle. In Kolb's learning cycle, the activity of reflection figures prominently and involves active consideration of one's experience, especially the degree to which it fits with one's understanding. Kolb draws directly on the work of John Dewey, whose philosophy has had an enduring influence across the broad field of education. Scholars have noted that "reflection" is a vague term that runs the risk of becoming unhelpful. In response, Rodgers (2002) identified four criteria distinguishing Dewey's definition of reflection: reflection is a meaning-making process, a rigorous way of thinking, in a community, and a set of attitudes. In addition, Dewey's distinction between educative and "mis-educative" experiences is helpful for distinguishing "good" reflective practices. Experiences are mis-educative to the degree that they have "the effect of arresting or distorting the growth of further experience." (Dewey, 1938, p. 25). For Dewey, the process of understanding is broadly similar to scientific inquiry, and reflection is a vital aspect of that process.

\section{Intercultural learning}

I define intercultural learning as "becoming more inclined to see, value, and respond to others and one's own culture." This definition is intentionally narrow to keep the central argument as clear and specific as possible. The field of education abroad is filled with different definitions of intercultural learning, each capturing something valuable (Deardorff, 2006). For example, becoming more proficient at speaking another language is a part of many definitions of intercultural learning. Similarly, knowing a country's history, current events, religion, and traditional and modern cultures is an important component. Being able to interact appropriately with people from another culture is vital as well. Finally, gaining self-confidence, appreciating the life one has, and other forms of personal growth are important education abroad outcomes.

The definition I chose focuses on perceptions of others and one's own culture and is in close alignment with the definition of intercultural sensitivity put forth by Bennett (1993) and Hammer et al. (2003). In their work, intercultural sensitivity is a quality of "one's experience of cultural difference" (Hammer et al., 2003, p. 423). Higher levels of intercultural sensitivity are marked by a shift from ethnocentric to ethnorelative perceptions of differences between one's own and other's cultures. Presumably, increased intercultural sensitivity is associated with a greater likelihood of productive interactions with others who are culturally different.

The definition I chose also focuses on inclination: becoming more inclined to see, value, and respond to others and one's own culture. An inclination is a natural, spontaneous quality of a person, as contrasted with something more intentional and reasoned. Thus, intercultural learning not only involves adopting a more ethnorelative stance, but doing so spontaneously and wholeheartedly.

Honesty

Honesty is the quality of being free of deceit and untruthfulness. To be honest is to be sincere (Oxford Dictionaries Online). In the context of intercultural learning, honesty refers to being 
truthful when recounting experiences. In addition, honesty is a quality of truthfulness to both others and oneself.

Ritual

Rituals are associated with important occasions such as weddings, graduations, professing feelings or faith, entering into a community, starting a job, and coming of age. Rituals are filled with meaning and significance made public through the symbols and activity of the ritual. The Oxford dictionary defines ritual as:

A religious or solemn ceremony consisting of a series of actions performed according to a prescribed order (Oxford Dictionaries Online).

How is guided reflection a ritual?

Let's examine each of the distinctive qualities in the Oxford definition and apply them to qualities of guided reflection.

Solemn. Like participants in a ritual, students participating in guided reflection are expected to also be serious. Good reflection can be described as thoughtful, profound, wise, deliberate - all qualities that also describe the solemnity of a ritual. Solemnity refers to the tone of a ritual and, by itself, does not necessarily detract from honesty. However, it does highlight how a ritual conforms to certain expectations.

Ordered. Rituals have distinct parts, almost always performed in a certain order. Similarly, guided reflection almost always begins with the facilitator asking some variation of the question, "Describe what occurred and your reaction to it." Then, the facilitator will help students think "deeper" about their experiences. They will be prompted to go beyond describing what happened to describing how they felt and what they thought. Pushed further, they may be asked to consider the meaning and significance of the experience. Guided reflection often concludes with the facilitator asking questions such as, "How has your understanding of the situation or yourself changed?"

Prescribed. To prescribe is to assign or permit by authority. In a ritual such as a traditional wedding, an official organizes and presides over the ritual. In the case of guided reflection, students are reflecting in response to an instructor's request. In addition, the instructor presides over the reflection by initiating, guiding, and ending the activity.

Performed. A ritual is a performance. This particular characteristic, above all others, is the reason why guided reflection may not be well suited to support intercultural learning. To perform is to carry out a prescribed activity. Participants come prepared having rehearsed and observed others perform the same ritual. Similarly, education abroad students are very familiar with the activity of reflection-it is modus operandi in humanities and social science courses. In any liberal arts curriculum, deliberate reflection on one's experience is both the goal and the process of learning.

Rituals are successful to the degree that participants perform their prescribed roles as they are supposed to. Participants and observers alike understand what a good performance looks like. Likewise, students have a clear understanding of what counts as a "good" guided reflection based on extensive prior experience. The markers of a good reflection include a detailed description of 
one's experience, willingness to self-question, capacity to acknowledge the limits of one's perspective, and openness to change. Just as Olympic figure skaters must demonstrate specified moves and jumps, students must successfully perform required elements during guided reflection. And, like a figure skating judge, the instructor has the power to evaluate and reward a good performance.

\section{A mismatch for intercultural learning?}

The focus on performance in guided reflection may be the quality that detracts most from students' intercultural learning. Educational psychologists have long distinguished activities that emphasize performing from those that emphasize learning (Butler, 1987; Dweck, 1986; Mueller \& Dweck, 1998). Students focused on performance are primarily concerned with doing well in the presence of others. By contrast, students focused on learning pay less attention to the evaluation of their performance and more attention to improving and understanding. For some scholars, the difference between performance and learning orientations represent two completely different mindsets towards a task. Students' orientation is associated with other aspects of motivation such as their task choices, persistence, learning strategies, focus of attention, and emotional responses.

The point is not to argue that a learning orientation is always preferable to a performance orientation. The performance orientation is embedded in how students are assessed and rewarded all the time in school. It is unreasonable to think that the structural and institutional elements of schooling will change easily. Furthermore, the performance orientation has adequately supported many important kinds of learning: for example, the acquisition of factual knowledge and skills.

However, the performance orientation may be an exact mismatch with the conditions needed to support intercultural learning. Global learning is challenging: it requires great persistence, criteria for success are ambiguous, truthfulness is essential, the experience may threaten the ego, the goal is deep understanding, and higher cognitive strategies are used. Research has consistently shown these characteristics are rarely associated with the performance orientation - the orientation evoked by the ritual of guided reflection (Mueller \& Dweck, 1998).

\section{Returning to King Lear}

In the opening scene of the play, Cordelia has no words of love for her father. However, by the final scene, we have no doubt Cordelia is the embodiment of the truest kind of love a daughter can have for her father. Shakespeare's genius is on full display in the way he convinces us of the honesty and sincerity of Cordelia's love.

In what might be a most unexpected move, Shakespeare puts Cordelia in situations that actually prevent her from directly expressing her feelings to King Lear. To begin, she is off-stage for much of the play and thus, there is hardly any dialogue with her father. But, while Cordelia is off-stage, the audience learns she leads an army in an ill-fated attempt to free King Lear, who is being held captive. Because these events are off-stage, we know only of Cordelia's actions, not her words. Thus, Cordelia's actions alone express her feelings for her father. In addition, her actions are spontaneous, rather than planned, requested, or prescribed.

Before she is executed, Cordelia is briefly reunited with King Lear. However, Shakespeare has made this scene into something quite the opposite of the opening scene. With King Lear dying and 
powerless, there is nothing of material value at stake. And, the sense of ritual around the king-so prevalent before-is greatly diminished in his fallen state. Furthermore, with the king slipping in and out of madness, there is little sense that Cordelia's words will be comprehended or appreciated. Nevertheless, these seemingly impossible conditions allow Cordelia's love to be more, not less, apparent. Far from the ritualized setting of the first scene, the conditions of their final scene together assure us that Cordelia's expression of love is honest and sincere.

\section{If not guided reflection, then what?}

Shakespeare's King Lear brilliantly illustrates how honest and sincere expression of one's personal thoughts and feelings is elusive, especially in situations evoking a strong sense of ritual, social norms, or extrinsic consequences. In education abroad programs, the ritualized nature of guided reflection activities makes it challenging for students to honestly consider their intercultural experiences. What can be done? Perhaps, education abroad programs can create situations that release students from the typical norms and rituals associated with intercultural learning. Granted, this might be construed as creating a new set of norms, but perhaps the result would be less ritualized. Here are several suggestions for the new norms. Phrased in a negative form, common for describing moral standards, the intent is to present these ideas in a way that is stark and contrasting, rather than severe and critiquing.

Don't act like a good student.

A central feature of ritualized activity is a concern for performing properly. In education activities, a good student is someone who acts - a word chosen deliberately - as a good student should. To say "don't act" means to be less concerned about performance and what you're supposed to do. Instead, focus more on learning and becoming better at something. Motivation should be intrinsic, rather than extrinsic. That is, the activity should be done for its own sake, not for external reasons such as a reward or approval. Intrinsic motivation is also characterized by curiosity, selfdirection, seeking challenges, and persisting in difficult situations.

It would be a mistake to assume changing from a performance to learning perspective also changes the importance of evaluation. The focus of evaluation changes from external criteria to more individual, internal qualities such as the degree to which experiences are becoming more enjoyable, effective, or meaningful. Furthermore, students must judge these qualities of their own experiences for themselves.

Ironically, I suspect that the "good" students will struggle most with this. These students have been academically successful precisely because they are keenly attuned to what they need to do to get a good evaluation in school. In other words, they are experts in performing academic rituals, such as guided reflection. These students are well-aware and care about what external criteria count as "good." In this alternative approach, there is not an outside evaluator, nor a clear standard of performance to meet. Instead, learning is evaluated according to a pragmatic, rather than normative, standard. In other words, students should consider questions such as, "Have I noticed changes in how I experience and behave in intercultural situations?" and "What value do these changes have for me?" This is in contrast to "What changes should I be experiencing?" and "Do other people—such as my instructor and peers—value these changes?” 
Don't work so hard.

To reflect comes from the Latin "to bend back"- suggestive of its effortful nature. In reflection, we "work things out," "search for meaning," "tackle problems," "confront issues," and so on. Reflection is associated with "constructing" meaning-what epitomizes work more than "construction"? Such constructivist learning theories are firmly grounded in the Western philosophical tradition that focuses on the rational, intentional, effortful aspects of learning. Furthermore, reflection and constructivist perspective have an implicit, but unmistakable, moral tone. A learner is a disciple, we learn disciplines, we become disciplined. In the Western Puritanical ethic, hard work is "good." When a person is described as "hard working," we are not only describing his activity, but his character. He is a good person by virtue of working hard. Thus, the ritual of reflection has deep moral overtones. The act of reflection itself is virtuous because it is hard work. Even better, when the subject of reflection is something difficult, when we tackle a challenging problem, we may be even more virtuous. With so much at stake, the ritual of reflection becomes very much like the opening scene of King Lear.

Consider an example from my own experience. What happens when one faculty person from my own College of Education asks another, "How was your weekend?" This question is basically a prompt for reflection. In the response that follows, I can almost guarantee the other faculty will use the word "busy," and that "busy" will be used to paint an image of his unending hard work and weary suffering. Performed well, his recounting of the weekend will elicit quiet admiration from me, other colleagues, and, especially, graduate students (undergraduates seem less affected by this performance). Once, when asked by a colleague about my weekend, I tried something different. I told her about a relaxing, enjoyable two days. "Oh! That's nice!" she exclaimed, an exaggerated smile stretched over gritting teeth. This "How Busy We Are" ritual is repeated over and over in the stairwell and hallways of my building. Through this ritual, faculty know what to do when they bump into each other. Through this ritual, faculty know how to behave regardless of how they really feel. (Who really wants to know about our existential angst when asking, "How are you doing?") Finally, through this ritual, members of my College give testimony and confirmation to its core ethics and morals: hard work is good.

When reflection and learning in general are equated with hard work, we cannot escape the moral implications. And, the moral tone compounds the urgency to do things properly and the consequences of doing it improperly. Thus, "Don't work so hard" is a call to release students from the morality play that characterizes ritualized learning activities, such as guided reflection.

\section{Don't think so hard.}

There's a second reason to not work too hard: Not all learning comes from deliberate effort. True, we humans have the capacity for reason. However, often overlooked is our equally human capacity to sense and intuit meaning - the opposite or complement of reason and effort (Wong, 2007). Although educators typically give little credence to non-rational, non-effortful ways of knowing, philosophical traditions have recognized that understanding the world requires more than reason and intentional effort (for example, Romanticism, Nietzsche, Schopenhauer, Kierkegaard, Sartre, Camus). However, because an ordered, controlled society requires its people be responsible for their actions, the intentional thinking aspect of human nature has been elevated to be virtuous and "good." 
As mentioned at the beginning of this piece, the philosophy of John Dewey is frequently cited as a basis for a rational approach — characterized by intention and logic-for guided reflection. However, in much of Dewey's work, particularly about aesthetics, he clearly emphasizes the necessity of both the rational and the non-rational, both intentional doing and what he called "undergoing." In Art as Experience, Dewey wrote, "There is . . . an element of undergoing, of suffering in its large sense, in every experience. Otherwise, there would be no taking in of what preceded" (Dewey, 1934). Dewey's "suffering" and "undergoing" capture the qualitative sensingthe non-rational, non-intentional-human capacity that complements reasoning and intention. Preeminent Deweyan scholar Philip Jackson contrasts qualitative sense and conscious reflection: "What Dewey is saying is that we sense or feel the situation we are in without thinking of it per se, without it becoming an object of reflection" (1998, p. 21). Thus, for Dewey, intelligent activity is the integrating of rational thinking and non-rational sensing, of intentional reflecting and spontaneous intuiting.

Additionally, in the push to construct meaning, guided reflection activities often move too quickly from the experience itself to what the experience signifies. To consider the "significance" of an experience is to focus on what it points to rather than the experience itself. We ask, "what is this experience an example of?" rather than "what exactly is happening in this experience?" Thus, intercultural learning might be better supported if we encouraged more and longer periods of uninterrupted observation. Also, a greater emphasis can be place on describing the details of the intercultural experience itself, rather its meaning and significance.

Finally, the request, "don't think so hard," is intended to encourage students to release themselves from the self-consciousness that has prevented them from being anything more than proper and careful. At the conclusion of his "to be or not to be" soliloquy, Hamlet describes how thinking about the consequences of our actions can turn us away from our initial resolutions.

Conscience does make cowards of us all,

And thus the native hue of resolution

Is sicklied o'er with the pale cast of thought,

And enterprises of great pith and moment

With this regard their currents turn awry,

And lose the name of action. (Shakespeare, Hamlet, Act 3, Scene 1)

Intercultural learning often requires a courage to break away from our familiar ways of seeing and doing things. An impulse must be acted on, a chance must be taken to gain a different perspective. Similarly, when students are too self-conscious, they may be less open to experience, inspiration, and creative impulses. Optimal experience (flow) and flashes of insight often come during a state of relaxed attention, rather than deliberative thought.

Don't talk so much.

There are both obvious and less obvious reasons for students to not talk so much. Indeed, groups of education abroad students-especially Americans-can be very loud and rude. Also, when education abroad students talk to each other while out and about, they are paying less 
attention to the world around them and interacting less with people outside their own group. Thus, within group talking inhibits intercultural learning because it diminishes intercultural interactions.

Before proceeding, let's examine why we have such deep beliefs that talking is essential to learning. First, in the constructivist view—often referenced by proponents of guided reflectiondialogue among students and instructor is perhaps the most important component. Why do we believe learning requires talking? The origins of this deeply rooted belief can be traced to Greek philosophy's dialectics ("the nature of the dialogue"). For Aristotle, Socrates, and Plato, the only method of arriving at truth was through public dialogue: logical argument and counter argument. The interconnection of rational thinking, public dialogue, understanding, and truth emerges from this point in Western history. The privileged relationship between rational thought, critical dialogue, and truth was further sanctified by $17^{\text {th }}$ and $18^{\text {th }}$ century Western philosophy and science. History tells us that rationality as expressed through logical critical dialogue is an important reason the world was "made luminous" in the Age of Enlightenment. It is difficult for Westerners to see the special status given to language and its "intrinsic sacredness" (Pirsig, 1974). Yet, the exceptional power of words in Western culture is not hard to see once we look for it. "My word is my bond." "I solemnly swear to speak the truth, so help me God." "In the beginning was the Word, and the Word was with God, and the Word was God." Even, "A picture is worth a thousand words," where a picture may be powerful, but words are still the currency.

Second, because words can have such power, they are almost always a key part of rituals. Weddings, graduations, swearing-in ceremonies, and rites of passage are all distinguished by specific language. We recognize rituals by the language; we learn rituals by learning the language. Granted, behavior, dress, and setting also play an important role in rituals. However, few things are more powerful than language in distinguishing the formal from informal, the special from the ordinary, the sacred from the profane. Furthermore, control and mastery of language distinguishes the insider from the outsider, the qualified from the unqualified, the higher authority from the lower. In academic settings, many have argued that to learn a particular discipline is, in essence, to master its language. If we emphasize the role of language in learning, we unavoidably bring to the fore the socio-political qualities of learning (Lemke, 1990). That is, if we assume learning special language is learning to participate in a discipline, we must also acknowledge that this language is a system created by others with power and control. Thus, the more we emphasize the importance of language, the greater the pressure to perform, perhaps conform, properly.

In sum, language has power. Power because of its association with rationality and progress in Western civilization. Power because of its central role in ritualized activities. Power also because of the theoretical perspectives where language and thought are inextricably connected. In these psychological theories (Vygotsky, 1978), to use language is to think. To learn language is to learn to think. In one of his less graceful quotes, Dewey affirms the power of language, "Language is the tool of tools" (Dewey, 1938).

There's no denying the special status given to language. However, our privileging language makes it difficult to consider other possibilities for how intercultural learning might occur. Here are three examples. First, not all learning is public. In guided reflection, the language usage is typically public. We should question whether public dialogue is always the only, or even best, means 
of learning. Intercultural learning can be intensely personal and may be best construed as a private experience. Students should be encouraged to explore more private forms of language-personal journal writing is one example. Second, not all aspects of intercultural experiences can be expressed in language. To ask students to express themselves in words may not fully capture or might even distort their experience. Finally, actions speak louder than words. Although well-worn, this idiom highlights the importance of behavior relative to language (in a way that ironically still privileges "speaking"). As educators, we ultimately want to change how our students conduct themselves, not just how they talk about what's in their hearts and minds.

\section{Conclusion}

"I couldn't believe what I was hearing." That was my reaction to what my education abroad students were saying during our reflection session. Not only was I in disbelief at how their description of an intercultural experience could be so different from what I had observed, I was also disbelieving the truthfulness of what they were saying. I doubt that my students were hallucinating or lying; instead, they were simply performing the familiar ritual evoked by that situation. When reflecting on their intercultural experiences, education abroad students are supposed to be positive and supportive.

We cannot avoid rituals and most often we should not avoid them. Rituals serve important social and cultural functions. First, rituals help us know how to behave in important public situations. When all eyes are on us and something is at stake, what should we do? Ritualized activities help us by specifying appropriate actions and words. But, because rituals emphasize a prescribed performance, we cannot be assured that the words and actions are honest expressions of participants' thoughts and feelings. In Act I of King Lear, the two older sisters' soaring words of love for their father perfectly suit this public ritual, yet probably betray their true thoughts. Similarly, when academic colleagues are asked about their weekends, they are unlikely to talk about how they didn't work that hard or, even less likely, enjoyed not working.

Second, rituals also help us in situations where we are confused or don't have much at all in the way of knowledge, feeling, or opinion. My education abroad students may have had mixed up thoughts about what happened during their teaching experience. The ritual of reflection gave them a way to "go through the motions" without drawing unwanted attention to their ignorance or incompetence.

It is worth emphasizing that ignorance is generally perceived as a liability. Being "ignorant" does not have the literal, denotative meaning of not knowing or being aware about something. Rather, being ignorant also carries the connotative meaning of being insensitive and bigoted. In academic contexts, it is prudent to avoid being perceived as ignorant. Significantly, this is particularly true in education abroad programs that emphasize intercultural learning where the focus is often on identity, power, and privilege. Here, the repercussions of being ignorant are even more serious. As result, the pressure to behave with propriety is even greater. When reflecting on intercultural experiences, it has become popular to designate the activity as a "safe space." However, these spaces are not intended to protect the ignorant, just the opposite. Safe spaces are intended to protect others from the ignorant. As such, conventions for language and behavior are strictly enforced. Thus, safe 
spaces are every bit a place for ritual as the opening scene of King Lear. Proper performance, not honesty, is the highest priority.

This piece is founded on the assumption that honest consideration of one's experiences is essential for intercultural learning. At the beginning, I cited examples from my education abroad program and from King Lear to illustrate how honesty is elusive in settings that evoke proper, ritualized performance. Next, I offered four new behavioral conventions to help students free themselves from the constraints of academic rituals: don't act like a good student, don't work so hard, don't think so much, and don't talk so much.

In closing, I add three virtues that characterize the good intercultural learner. Now, good students can be characterized by a number of virtues. However, many of these virtues inadvertently reinforce the importance of properly performing academic rituals: for example, conscientious, responsible, diligent, respectful. Thus, the following three virtues characterize students who can break free from the constraints of academic rituals.

Of course, the first virtue is honesty. Without honest consideration of one's intercultural experiences, becoming more interculturally aware, knowledgeable, and competent is impossible. The rituals of academics — such as guided reflection—have an inhibitory effect on individuals' capacity to consider their experiences honestly.

The second virtue is ignorance. When students experience ignorance, they are uninformed, confused, or unaware. These experiences of ignorance are precisely the moments in which genuine learning can emerge. The experience of ignorance is challenging, even distressing. As a virtue, ignorance is an ideal to sustain, rather than a temporary condition to pass through. Ignorance is an individual quality to be protected, rather than persecuted.

The third virtue is courage. Courage is a necessary companion of ignorance as it distinguishes very different kinds of ignorance. Ignorance with a prideful courage becomes willful ignorancestupidity. Ignorance without any courage is a passive ignorance-naivety. However, ignorance accompanied by a humble courage is an open-minded ignorance-curiosity. Curiosity is most likely to lead to personal growth and intercultural learning. It takes courage to realize one's ignorance in intercultural experiences, to take these experiences in, to be curious about how to be less ignorant, and, finally, to think and behave differently.

\section{References}

Bennett, M. J. (1993). Towards ethnorelativism: A developmental model of intercultural sensitivity. In R. M. Paige (Ed.), Education for the intercultural experience (pp. 21-71). Yarmouth, ME: Intercultural Press.

Butler, Ruth (1987). Task-involving and ego-involving properties of evaluation: Effects of different feedback conditions on motivational perceptions, interest, and performance. Journal of Educational Psychology 79(4), 474-482. http://dx.doi.org/10.1037/0022-0663.79.4.474

Cohen, A. D., Paige, R. M., Kappler, B., Chi, J.C., \& Lassegard, J. P. (2005). Maximizing education abroad through language and culture strategies: Research on students, education abroad program professionals, and language instructors. Minneapolis, MN: Center for Advanced Research on Language Acquisition. University of MN. 
Deardorff, D. (2006). Identification and assessment of intercultural competence as a student outcome of internationalization. Journal of studies in international education, 10, 241-266. https://doi.org/10.1177/1028315306287002

Dewey, J. (1938). Experience and education. New York: Touchstone Press.

Dewey, J. (1934). Art as experience. New York: Perigree.

Dweck, C.S. (1986). Motivational processes affecting learning. American psychologist, 41(10), 10401048. http://dx.doi.org/10.1037/0003-066X.41.10.1040

Engle, L. (2013). What do we know now and where do we go from here? Opening Plenary. The Forum on Education Abroad, Chicago.

Hammer, M., Bennett, M., \& Wiseman, R. (2003). Measuring intercultural sensitivity: The intercultural development inventory. International journal of intercultural relations, 27(4), 421-443. http://dx.doi.org/10.1016/S0147-1767(03)00032-4

honest [Def. 1]. (n.d.) In Oxford dictionaries online, retrieved July 12, 2016 from https://en.oxforddictionaries.com/definition/us/honest

Jackson, P. W. (1998). John Dewey and the lessons of art. New Haven: Yale University Press.

Kolb, D. A. (1984). Experiential learning: Experience as the source of learning and development. Englewood Cliffs, NJ: Prentice-Hall, Inc.

Lemke, J. L. (1990). Talking science: Language, learning, and values. Norwood, NJ: Ablex Pub. Corp.

Mueller, C. M., \& Dweck, C. S. (1998). Intelligence praise can undermine motivation and performance. Journal of personality and social psychology, 75(1), 33-52. http://dx.doi.org/10.1037/00223514.75.1.33

Pirsig, R. M. (1974). Zen and the art of motorcycle maintenance. London: Bodley Head.

ritual [Def. 1]. (n.d.) In Oxford Dictionaries Online, retrieved July 12, 2016 from http://www.oxforddictionaries.com/us/definition/american_english/ritual

Rodgers, C. (2002). Defining reflection: Another look at John Dewey and reflective thinking. Teachers college record, 104(4), 842-866. doi: 10.1111/1467-9620.00181

Shakespeare, W. (1999). King Lear. S. Orgel (Ed.) New York, N.Y: Penguin Books.

Shakespeare, W. (2016). Hamlet. (A.R. Braunmuller \& S. Orgel, Eds.) New York, N.Y: Penguin Books.

Vygotsky, L. S., \& Cole, M. (1978). Mind in society: The development of higher psychological processes. Cambridge: Harvard University Press.

Wong, E. D. (2007). Beyond control and rationality: Dewey, aesthetics, motivation, and educative experiences. Teachers college record, 109(1), 192-220.

Wong, E. D. (2015). Beyond It was Great? Not so fast! A response to the argument that education abroad results are disappointing and that intervention is necessary to promote students' intercultural competence. Frontiers: The interdisciplinary journal of education abroad, 26, 121-135. 